\title{
Chronic Stress-An Etiological Agent for the Genesis of Multitude of Diseases, and the Effect of Meditation on Modulating the Stress
}

\author{
Dr. Malireddy S Reddy* \\ International Media and Cultures, Inc. (IMAC), and American Dairy and Food Consulting Laboratories, Inc. (ADFAC), Denver, CO 80231 USA
}

Submission: June 24, 2017; Published: August 21, 2017

*Corresponding author: Dr. Malireddy S Reddy, BVSc (DVM), MS, PhD, President and CEO American Dairy and Food Consulting Laboratories, Inc. (ADFAC) And International Media and Cultures, Inc. (IMAC) 1280 So. Parker Road Denver, C0 80231, USA, Email: drreddy@askimac.com

\begin{abstract}
This review/research article is written to explain in detail the pathophysiology of the chronic stress syndrome, which will ultimately leads to several diseases. Panic circumstances under which this chronic stress syndrome develops and induces anxiety, fear and diseases are thoroughly outlined. The negative effects of the chronic-low-level stress on the gastro intestinal tract and its micro flora, including Probiotics, have been presented with explicit details. The positive effects of meditation on curbing the stress and stress related diseases have been discussed, particularly with reference to the effect of meditation on controlling or modulating the stress inducing hormones.
\end{abstract}

Keywords: Fight or flight response; Stress; Chronic-low-level stress; Stress syndrome; Meditation; Probiotics; Obesity; Hypertension; MS Reddy's Multiple Mixed Strain Probiotic Therapy.

\section{Introduction}

This article is written in a simplified fashion so that both the medical as well as non-medical professionals can read and understand the patho-physiology of stress and its control or management through meditation. In my opinion, stress is the major cause of several diseases, and if it can be controlled without using severe medications (which give unpleasant side effects), the entire humanity will be making a step in the right direction to curb the unnecessary human suffering.

\section{What is stress?}

Before we go into specifics of this subject, let me define the stress. The following is my simplified version of the meaning of stress. Stress is a multi-factorial syndrome negatively affecting various organs in the body through acute or chronic excitement of the sympathetic nervous system and subsequent repairable or irreparable, major or minor, hormonal imbalance. Stress can be induced physically or through vivid negative mental imagination (which is not real), because human being has the most well developed central nervous system, which is capable of dreaming both negative as well as positive aspects of the past as well as the future (with equal intensity). Stress is the ultimate root cause for the genesis of several diseases including but not limited to heart attacks, stroke, irritable bowel syndrome (IBS), chronic constipation, Eco imbalance in the GI tract (reduction of number of Probiotics in relation to the non-Probiotic harmful microorganisms) leading to hypercholesterolemia, allergies, migraine headaches, pulmonary diseases, autoimmune diseases, arthritis, premature aging, chronic fatigue, depression, obesity, hypertension, diabetes, vulnerability to various bacterial and viral infections due to hypoactive immune system, immune deficiency diseases, certain cancers, Alzheimer's, and various other unexplainable metabolic disorders.

\section{How does stress manifest itself in the human body?}

Let me summarize it in a simplified format the pathophysiology behind the 'fight or flight' mechanism which will ultimately result in a chronic stress syndrome. Fear starts the fight or flight mechanism, which exists in the body, to protect us from the perceived danger. When somebody is confronted with an unexpected danger, such as a tiger suddenly appearing in front of you in a forest etc., the immediate response is to either fight or run away from the scene. This fight or flight mechanism and the physiology behind it was originally discovered by the Harvard Physiologist Dr. Walter Cannon. It is designed to protect us from the bodily harm, when we experience excessive fear 
or panic either from internal worry or external circumstances. When we are confronted with any enemy who can hurt us either physically or through verbal abuse, the following sequence of involuntary events take place in our body: the eyes and ears or both send the information to the amygdala, an area of the brain that contributes to the emotional processing.

The interpretation of the intensity of panic scene is done by the amygdala. When it perceives a real danger, it instantly sends a distress signal to the hypothalamus. The hypothalamus then activates the sympathetic nervous system by sending signals through the autonomic nerves to the adrenal glands. As a response, the adrenal glands produce and pump the hormones epinephrine (adrenaline) and nor epinephrine into the blood stream. These hormones which are being circulated by blood brings about a series of physiological changes in various parts of the body. They are as follows: the heart starts beating faster; pulse rate and blood pressure go up; rapid breathing; increased blood supply to the muscles, heart and other vital organs; decreased blood supply to the GI tract; release of excess blood sugar and fats (fatty acids) into the blood to increase the energy to all parts of the body. All of these above reactions happen in a spur of the moment, without even a slightest notice to the person experiencing it.

As a second step, after the initial surge of epinephrine and norepinephrine subsides, the hypothalamus activates the second component of the stress response called "HPA Axis", which involves Hypothalamus, Pituitary gland and the Adrenal glands. If the brain continues to perceive the danger, the hypothalamus releases Corticotrophin Releasing Hormone (CRH), which travels and triggers the production and release of Adrenocorticotropic Hormone (ACTH) by the pituitary gland. The ACTH hormone instantly activates the adrenal glands to release cortisol. This cortisol maintains and improves (by acting as a booster to the fight or flight mechanism) the physiological changes already brought about by epinephrine and norepinephrine, to cope up with the persistent danger. When there is no longer a threat, the levels of cortisol drop gradually and the parasympathetic nervous system gets activated to dampen or negate or put a break to the stress response.

Figure 1 shows the location of endocrine glands (Pituitary and Adrenal) involved in the production of hormones which have direct influence on fight or flight mechanism. I have also included the glands that are indirectly involved, such as islets of Langerhans in the pancreas, which get activated to produce more glucagon and insulin to convert glycogen to glucose and also to improve the uptake of glucose by the activated cells of stimulated tissue. In addition, the endocrine glands involved in the production of estrogen and testosterone have been pointed out to show the negative effects of low level stress to reduce the production of sex hormones, which will ultimately result in the lack of interest in sex (reduced libido), impotency, erectile dysfunction, osteopenia, osteoporosis, sarcopenia etc.

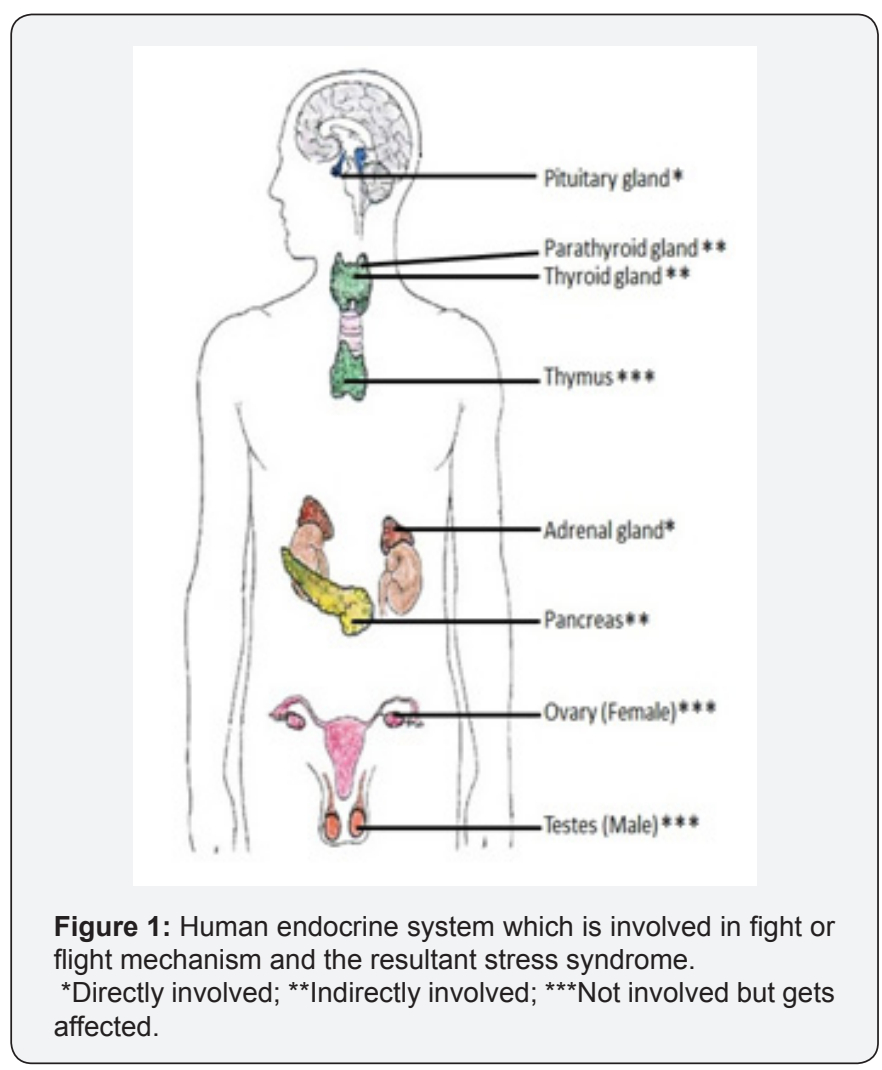

\section{Effects of chronic-low-level stress}

Unfortunately several individuals are unable to put breaks on stress and end up living with chronic low-level stress. This chronic-low-level stress keeps the HPA axis activated for a longer time than it is required (to maintain the level of cortisol in the blood and to reduce the effects of parasympathetic nervous system, which can dampen the stress syndrome). This chroniclow-level stress contributes to the onset of several health problems. The frequently repeated and persistent epinephrine surges will undoubtedly damage the blood vessels and arteries due to increased blood pressure, which will ultimately lead to heart attacks and strokes. In addition, the abnormally elevated cortisol surges (frequently repeated) in the blood will bring about physiological changes to replenish the bodies energy reserves that are depleted during the stress response. Unfortunately, such a physiological change contributes to the buildup of fat or adipose tissue which leads to obesity. Cortisol not only increases the appetite so that people can eat more to obtain extra energy, but also increases the storage of unused nutrients as fat. Thus stress could be one of the major contributing factors for the increased prevalence of obesity in America and elsewhere in the world.

Since the blood supply is severely reduced to the gastrointestinal tract, during stress or chronic-low-level stress, the digestion gets sluggish to the point of not breaking the proteins down to amino acids. Some of these not fully digested peptides when gain entrance into the blood stream may induce 
allergy due to the production of antibodies and their subsequent reaction when confronted with similar antigen. In addition, chronic-low-level stress due to persistent presence of cortisol hormone in the system enhances and maintains the effect of epinephrine and norepinephrine and thus decreases the blood supply and subsequent intestinal peristalsis, ultimately causing chronic constipation. The resultant constipation encourages the growth and proliferation of non-Probiotic transient and nontransient bacteria to convert amino acids tyrosine and histidine to toxic amines, tyramine and histamine $[5,6]$. The histamine induces vaso constriction and thus cause the hypertension and also premature aging. chronic-low-level stress induced constipation encourage some of the fecal micro flora to convert amino acids tyrosine to phenol and paracresol, and tryptophan to indol, which are highly carcinogenic. In addition, the enzymes produced by some of the stress activated dominant adventitious flora will convert procarcinogens to carcinogens $[5,6,9]$.

Lack of intestinal motility and subsequent constipation due to stress, will significantly reduce the Probiotic population and simultaneously increase the fecal adventitious microflora which produce the following enzymes to convert procarcinogens to carcinogens: Beta glycosidase, Beta glucoronidase, Steroid 7 alpha hydroxylase, Nitro reductase and Nitrate reductase, Azoreductase and Tryptophanase [5]. Although procarcinogens are not harmful, the converted carcinogens are genotoxic and thus can trigger cancer [9]. Lack of sufficient blood supply to the GI tract due to stress, the absorption of calcium and other minerals by both active (transcellular) and passive (paracellular) transport systems in the duodenum and ileum will be significantly reduced thus causing, over a time, both osteopenia and osteoporosis [4].

Reduction of Probiotics and their activity (due to stress) will greatly increase the absorption of toxins, formed in the GI tract, due to chronic constipation. According to Dr. Nagler of University of Chicago, some of the Probiotics can retard the absorption of allergens by signaling the innate immune cells to produce high levels of interleukin (IL-22), a signaling molecule known to decrease the permeability of the intestinal lining, thus preventing allergens to enter into blood stream [2]. However such mechanism may not be operational due to stress induced constipation, because of the significantly low number of Probiotics and sluggishness of the intestinal lining and decreased blood supply. Thus the entire human system can be disturbed because of the low level chronic stress.

Since the Probiotic bacterial numbers significantly come down during persistent stress, immune modulation gets effected leading to the immune deficiency $[7,8]$. Due to this immune deficiency and reduction of Probiotics, the opportunistic subdued pathogens (both bacteria and virus) will dominate in numbers and thus turn into virulent pathogens proning the individual to bacterial and viral infections. Since most of the Probiotics are nutritionally fastidious, it is extremely important to maintain good blood supply and intestinal peristalsis to produce and improve the activity of proteolytic and lipolytic enzymes, amino and carboxyl peptidases, and lactase enzyme etc. to enzymatically break and generate the simpler and easily assailable nutritional compounds to stimulate the growth and proliferation of Probiotics in the GI tract. Unfortunately due to significant reduction of blood supply (during stress) to the GI tract, the resultant improper digestion and the digestive end products of improper digestion cannot support the growth of Probiotics. Turn around, this will encourage the growth of nutritionally non-fastidious pathogenic as well as non-beneficial micro flora which will cause severe intestinal infections. The reduction of Probiotics and subsequent increase of other nonbeneficial micro-organisms, due to chronic stress, can ultimately result in irritable bowel syndrome, intestinal diverticulosis and colon cancer, and hospital acquired infections etc. [3,9]. It has been proven that replenishing Probiotics will reverse the C. diff and MRSA infections (nosocomial infections due to stress) using, Dr. M.S. Reddy's Multiple Mixed Strain Probiotic Therapy $[5,6,8]$.

Since chronic stress syndrome significantly reduces the blood supply, nutrients, and intestinal motility, it indirectly reduces the number of Probiotics and thus significantly reduce several physiological benefits of Probiotics [8]. In this article, I have only stressed the negative effects of chronic stress on the health of gastro intestinal tract, specifically with reference to reduction of Probiotics and the calcium and other mineral absorptions. Technically the genesis of hypertension, diabetes, and several other diseases can also be due to chronic stress because of the excitement of stress hormones on a periodic basis. If we can reduce the stress, several of these diseases can be eliminated or reduced.

According to the survey conducted by the American Psychological Association, about 25 percent of Americans (88 million people) are experiencing high levels of stress (8 or more on a 10 point scale). The low level of stress ( 4 to 7 on a 10 point scale) has been experienced by $50 \%$ of the Americans (to be precise 165 million people). In other words 253 million Americans out of 330 million people have been experiencing the chronic-low-level stress syndrome. To sum it up, every adult In the United States has been subjected to stress. No wonder why the medical costs are so high (along with increased number of diseases), despite the fact the nutrition and health awareness are more in the United States than any other country in the world. In my opinion, this chronic-low-level stress syndrome plaguing the American society is due to the uncertainties in economy, social problems, increased divorce rate, increased monthly obligations, job insecurity, and more than all fear and anxiety associated with the day to day living. The excessive use of cell phones, emails, and over communication is also contributing to this stress syndrome, which is a silent killer. I am sure, the majority of the population in the entire world must be going through this chronic-low-level stress syndrome, which is the genesis of multitude of diseases. 


\section{Stress in modern day life}

As a classical example, fight or flight response has always been referenced as tiger attacking human being. In today's world, the tiger is no longer a threat. Then what is it? The following are some of the examples: an unscrupulous boss or supervisor constantly behaving like a tiger and threatening the employee; a spouse behaving like a terrorist and physically or verbally attacking his or her partner repeatedly and violently; a government putting unnecessary stress on the people; and fear due to unknown reasons which lead to stress and anxiety etc. The fight or flight mechanism enables a person either to fight or flee away. Either way, the physical activity involved will reduce the levels of stress hormones (the novel concept behind physical exercise). Unfortunately, in this day and age, you cannot either fight with your boss or spouse or run away from them. Thus the stress hormones stay intact in the system and constantly induce the chronic-low-level stress syndrome, which ultimately results in a specific or multitude of sicknesses and diseases. Another stress factor is, constantly thinking about bad experiences encountered in the past, and also anticipating the troubles and problems you are going to face in the future. According to the Buddhist principles, delving into the unpleasant past memories will cause pain and suffering, whereas imagining about the future anticipated problems create anxiety and stress. It is because amygdala perceives past bad memories or anticipated future problems as threats and automatically activates the uncalled for fight or flight mechanism. If a person lives and thinks in the present (not in the past or future), the level of stress will be significantly low. In reality, the past does not repeat and future does not exist, yet these two factors are contributing to this unnecessary stress which is destroying the health of people and thus dampening the progress of the world.

\section{How does meditation relieve or eliminate stress?}

Stress can be eliminated through optimism and happiness. Since stress is a psychological factor involving the central nervous system and hormones, people have to learn to control it by understanding the pathophysiology behind the onset of this syndrome. The best way to control the stress syndrome is through development of positive mental attitude by practicing meditation. Several major medical organizations in the country, including their applied and basic researchers and scientists, are all in total agreement that the meditation is the best way to control the stress. Let me define and explain what meditation is? Meditation has no affiliation to any country, region, race or religion. Generally people relate the word meditation as part and parcel of Hindu religion, which is not true. Meditation was the brain child of the Hindu God "Lord Krishna", who taught this concept to the world, perhaps over 5000 years ago. The concept and practice of meditation was introduced to uplift the depressed souls who were afflicted with the stress syndrome in a battle ground.

Meditation is nothing but realization of the power of the inner soul (human potential) and integrating or uniting the soul with the mind and body, to direct the human actions in right path with least stress. There are several techniques to practice meditation. The best and simple approach is, give an imaginary shape to your subconscious, and communicate with the subconscious image on a daily basis regarding your goals, health, thoughts, and actions. Once you start to communicate with your own subconscious, your level of self-confidence will be greatly improved and thus you will not have any fear or anxiety or stress.

According to the ancient Vedic scripts, the human life simultaneously exist in two parallel dimensions. One is "physical body" and the other is imaginary or psychological (not physical) called "subtle body". The subtle body is considered as "energy", while the physical body is regarded as "mass". To put it in simple words, it is constantly referred to as "mind (brain, subconscious, subtle body) over matter (physical body)". The subtle body consists of NADI (energy channels) connected by nodes of psychic energy called chakras or energy centers. According to the yogic tradition there are seven energy centers in the subtle body. They are as follows in the ascending order from lower energy center (Muladhara) to the higher energy center (Sahasra kamala), connected by energy channels: Muladhara, Swadisthana, Manipura, Anahitha, Yashudhi, Agna, and Sahasra Kamala. The imaginary locations of these energy centers and the organs they influence are presented in Figure 2. Each energy center through activation supplies energy to the specified organs to keep them functional and healthy. According to Gardiner and Osborn [1], the chakras (energy centers) are described as metaphysical counter parts to the endocrine glands. The charkas (energy centers) are linked to the nerve plexus along the spinal cord, as per the description of Sturgess [11].

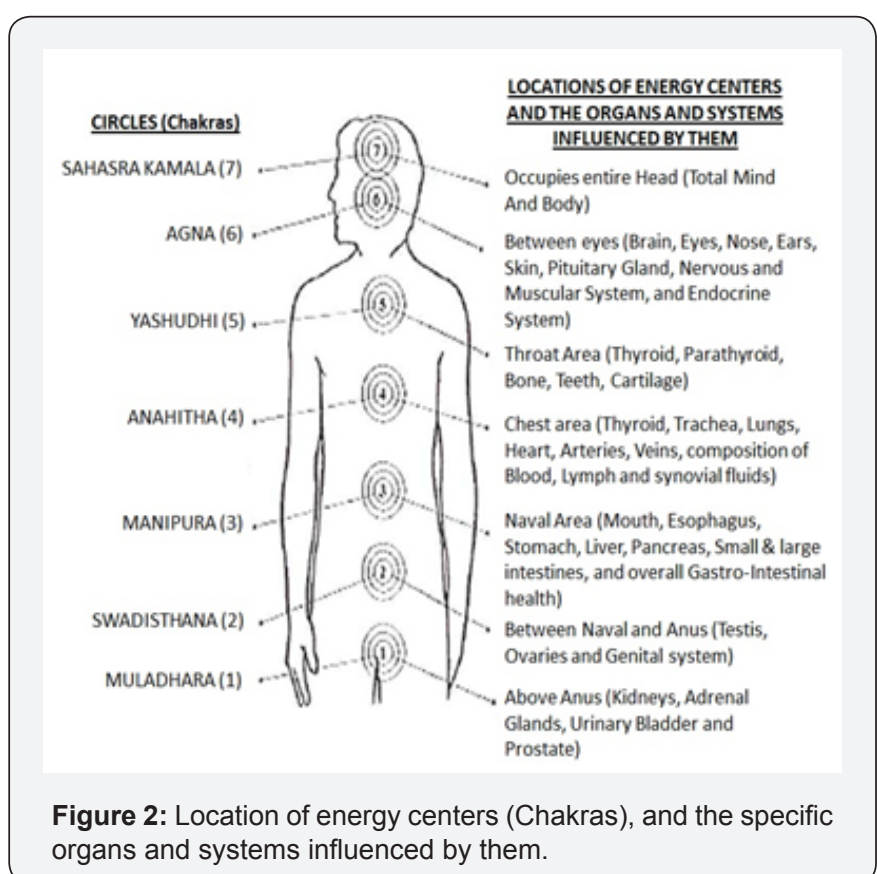

organs and systems influenced by them.

It can be argued, at this juncture, questioning that are these 
energy centers (chakras) real? If they are not real, how could we believe the mere existence of subtle body, including the energy centers and energy channels? The answer is very simple in that we all have thoughts and aspirations, can we physically feel the thoughts? Do they have any shape? My answer is no, because they are very subtle and controlled by imaginary subtle body. Since the endocrine glands are activated through the stimulus generated by mere imagination, we can safely assume and it has been proven that the endocrine activities are both psychological and neurological. Similarly, the imaginary energy centers have role in modulating the human endocrine system through the sympathic as well as parasympathetic nervous system. In other words, imagination (either positive or negative) drives the endocrine system. This is whole basis for the discovery of fight or flight mechanism by Harvard Physiologist Dr. Walter Cannon. Now it makes more sense with regard to the physiological and psychological functions of the energy centers (chakras), and energy channels of the subtle body.

The main subject of this paper is to discuss about the genesis of stress and how to control it by not using the drugs, which have serious side effects? Since stress is a psychological and neurological response to a situation, the treatment model should be to reduce such an adverse response, to eliminate the resultant chronic-low-level stress syndrome. This is where the meditation plays its role with the subtle body, energy centers and energy channels. One has to imagine that the energy centers (chakras) can be activated and churned to dissipate the energy, to the specified organs, to activate them and to make them more functional. The energy thus liberated from the energy centers greatly improves the health and outlook of the person and eliminates fear, anxiety and stress. In the Figure 3 , I have presented various energy centers and their influence on functions of specific organs. During meditation, one has to imagine and feel that they are in fact activating the energy centers to keep the organs functioning. It will only take few minutes but its psychological and neurological impact is significant and immeasurable in terms of improving the optimism, control of the central nervous system and endocrine system. Through practice of meditation, which is a psychological booster, the day to day stress can be significantly reduced and thus ultimately eliminate the chronic-low-level stress syndrome. The concept and practice of meditation is gaining significant momentum in the medical field, since there are no specific drugs to control the stress and its ramifications on health.

For example, we all know that the hypertension is an ailment or disease and a physician can only treat it by prescribing a specific drug. However, the genesis of hypertension, as it name implies "tension", stems from chronic-low-level stress. A drug can only try to keep the blood pressure normal (of course with other unavoidable bad side effects). In other words, the treatment is aimed at reduction of the symptoms only. In reality, the physician has not cured the main cause of the aliment, which is stress.
The only way to treat the main cause is through meditation which has direct influence on endocrine system and the central nervous system. Consequently the modern treatment should be aimed at using drugs to immediately reduce the life threating symptoms on a short term basis, and using body-mind therapy (meditation) on a long term basis to treat the genesis of the disease. The complementary and alternative medicine is gaining more popularity because the patients are not fully satisfied with the treatment they are receiving from their primary physicians. As I have indicated earlier, human being has advanced central nervous system which unfortunately responds involuntarily and negatively to the outside unpleasant or imagined as unpleasant circumstances and thus induce the chronic-low-level stress syndrome followed by multitude of diseases. Meditation controls the central nervous system and positions it in a proper perspective to react to the outside unpleasant or imagined as unpleasant circumstances voluntarily and positively, thus eliminating or reducing the stress and its pathological affects. The reduction of stress is the ticket for anti-aging.

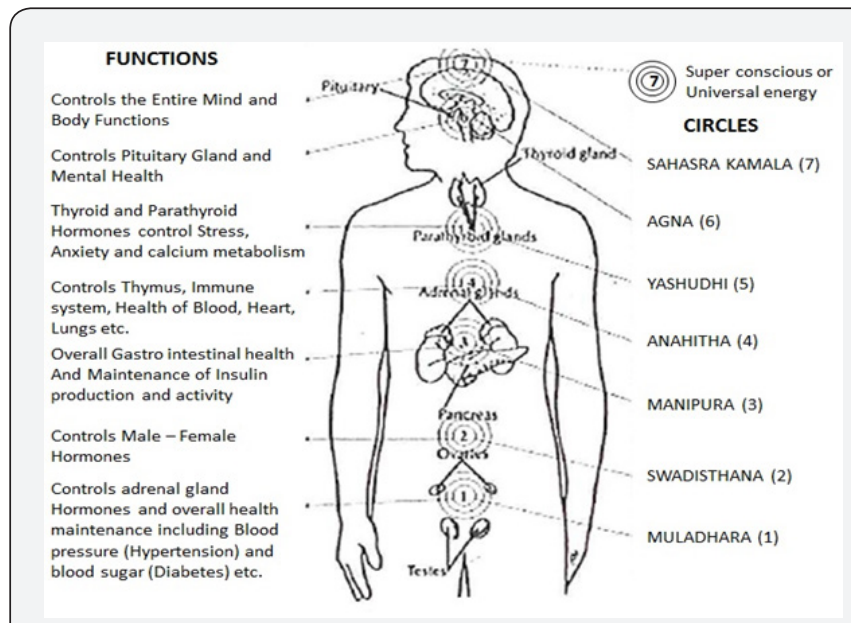

Figure 3: Effect of meditation on activating the energy centers and harmonizing the functions of endocrine system.

I have included graphic presentation of the hormones and organs controlled by seven energy centers which can be activated or harmonized through meditation (Figure 3). Meditation is an approved alternative medical practice which is governed by the division of the National Center for Complementary and Alternative Medicine (NCCAM), under the domain of MindBody medicine. The "NCCAM" comes under the umbrella of the National Institute of Health (NIH). Consequently any practicing allopathic Doctor in the United States can legally recommend meditation as a therapeutic aid to reduce the stress of his or her patients.

Several people question regarding how meditation can control or normalize the hormonal imbalance, which is experienced in chronic-low-level stress syndrome. Before answering this question, if you analyze it philosophically, stress is a psychological syndrome and even a person who is doing 
well in his profession or job or business gets stressed because he is constantly comparing himself with others. This creates a sense of insecurity, which diminishes self-confidence, resulting in inferiority complex in a person, which will in turn create constant mental agitation with an ingrained imaginary negative image of himself or herself. Thus he or she develops a chroniclow-level stress syndrome, which will subsequently lead to severe depression, unhappiness and irreparable bad health. Another cause for the stress is the inability of several human beings not able to do what they really wanted to do in life or not having an opportunity to do it. Greed destroys their beliefs and purpose of their lives, thus leads to unhappiness, stress, and disease. An individual who is carrying on duties (against his inherent passion) or in accordance with those dictated or expected by others will never be a happy soul. It is because he is fulfilling dreams of others with no full commitment, and such an action always gets criticized, which will lead to pessimism, unhappiness and such person ultimately develops chronic stress syndrome and diseases. Whereas, the man who carries on the duties in which he has inherent passion is always happy and thus keeps the stress syndrome at bay and leads a happy and healthy life. Self-satisfaction and commitment are extremely important to develop self-confidence and to eliminate fear and stress.

In my opinion, meditation gives inner strength, selfconfidence, healthy central nervous system, and the way we look at our life. If you scientifically analyze it, meditation alters the perception of the amygdala about the intensity of perceived danger and its intensity of subsequent reaction to activate the hypothalamus, pituitary gland and the adrenalin gland hormones involved in the fight or flight mechanism. In addition, through meditation the energy centers can be tuned to perform in harmony with the total central nervous system including the activation and timely suppression of hormones and the neurotransmitters. The effects of meditation have been scientifically proven to reduce hypertension, stress etc. A person who meditates looks at the threats in a different fashion (with least stress) than an ordinary human being who is always in a panic mode, and thus experiences high levels of stress. To summarize, since the genesis of several diseases are due to stress, let us put a genuine effort to eliminate this unnecessary evil (stress) to build a better world with happy and healthy people.

\section{Acknowledgement}

I sincerely thank Dr. Bellamkonda Kishore, MD, PhD, MBA, for his input in assisting me to interpret meditation and its influence on the reality of life. Thanks also goes to Dr. Siva Prasad Kumpatla, M.Sc (Ag), MS (Bio info), PhD, for his help in the preparation of figures, and to Ms. Renee Williams for typing the manuscript.

\section{References}

1. Gardiner P, Osborn G (2006) The shining ones: the world's most powerful secret society revealed (Rev. and updated ed). London: Watkins: 44-45. ISBN 1-84293-150-4.

2. Nagler C et al (2014) Gut bacteria that protect against food allergies identified. Food allergy and research education (FARE) publication available at: http:www.food allergy.org/press-room/2014/082514

3. Reddy MS, Reddy DRK (2009) Probiotic Therapy. AAPI Journal 3:2829.

4. Reddy MS, Reddy DRK (2011) Antiaging: review and experimental clinical study of bioavailable calcium Probiotics and their effect on reversing osteopenia, osteoporosis, and other common health conditions. International Journal of Pharmaceutical Sciences and Nanotechnology. 3:1436-1444, http:www.IJPSNONLINE.com/archives43.PHP

5. Reddy MS, Reddy DRK (2016) Development of Multiple Mixed Strain Probiotics for "Probiotic Therapy" under clinical conditions, to prevent or cure the deadly hospital acquired infections due to Clostridium difficile (C. diff) and Methicillin Resistant Staphylococcus aureus (MRSA). International Journal of Pharmaceutical Sciences and Nanotechnology 3:3256-3281, http:www.IJPSNONLINE.com/archives93.PHP

6. Reddy MS, Reddy DRK (2016) Isolation and Determination of the major principle of causative agent behind the 2016 published breakthrough discovery of Dr. M.S. Reddy's "in successfully treating the lethal hospital acquired infections due to Clostridium difficile (C. diff) and Methicillin Resistant Staphylococcus aureus (MRSA). International Journal of Pharmaceutical Sciences and Nanotechnology 6:3556-3566, http:www. IJPSNONLINE.com/current.PHP

7. Reddy MS, Reddy DRK (2016) Dr. M.S. Reddy's Multiple Mixed Strain Probiotic Therapy. J Pharm Nanotechno 4 (3): 15-28, https:// www.RROIJ.com/open-access/dr-MS-Reddys-Multiple-Mixed-StrainProbiotic-Therapy-.pdf

8. Reddy MS, Reddy DRK (2017) An insight into the 2016 Best Medical award winning breakthrough Microbial and Nanotechnology based discovery of Dr. M.S. Reddy's Multiple Mixed Strain Probiotic Therapy, to successfully treat the nosocomial infections. Nanotechnology and Nano Sci J, 1:102, http://HENDUN.org/journals/NTTS/NTNS-102.PHP

9. Reddy MS, Reddy DRK (2015) A preventative medical approach for cancer suppression. AAPI journal 06:36-39.

10. Reddy MS, Reddy DRK (2007) Improving health and longevity with Probiotics and Ayurveda (Proyurveda). American Bharathi (a U.S. publication of American Telugu Association): 16-27.

11. Sturgess S (1997) The yoga book: A practical guide to self-realization. Rockport, Mass. Element: 19-21. ISBN 1-85230-972-5. 
This work is licensed under Creative

Commons Attribution 4.0 Licens

DOI: 10.19080/OAJT.2017.01.555571
Your next submission with Juniper Publishers will reach you the below assets

- Quality Editorial service

- Swift Peer Review

- Reprints availability

- E-prints Service

- Manuscript Podcast for convenient understanding

- Global attainment for your research

- Manuscript accessibility in different formats

( Pdf, E-pub, Full Text, Audio)

- Unceasing customer service

Track the below URL for one-step submission https://juniperpublishers.com/online-submission.php 